\title{
BƯớC ĐẦU NGHIÊN CƯU KHU HỆ NẤM CHI COPRINUS PERS. ET GRAY TRÊN CAO NGUYÊN LÂM VIÊN
}

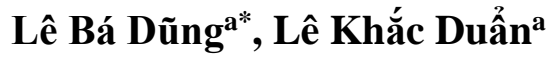 \\ ${ }^{a}$ Khoa Sinh học, Trường Đại học Đà Lạt, Lâm Đồng, Việt Nam \\ Lịch sử bài báo \\ Nhận ngày 01 tháng 07 năm 2016 | Chỉnh sửa ngày 26 tháng 08 năm 2016 \\ Chấp nhận đăng ngày 15 tháng 09 năm 2016
}

\section{Tóm tắt}

Khu hệ nấm chi Coprinus Pers. et Gray trên cao nguyên Lâm Viên gồm 6 loài sau đây: Coprinus sterquilinus (Fr.)Fr., Coprinus lagopus (Fr.)Fr., Coprinus heterothrix Kuhner., Coprinus disseminatus (Pers.)Gray, Coprinus plicatilis (Curtis)Fr. và Coprinus ephemeroides (Bull.)Fr., Trong đó loài Coprinus plicatilis (Curtis)Fr. được sủ dụng làm thực phẩm. Các loài nấm thuộc chi nấm mục thuờng sống hoại sinh trên phân hoạc trên đất vào mùa mura.

Từ khóa: Coprinus; Lâm Viên; Tây Nguyên; Việt Nam.

\section{MỞ ĐẦU}

Cao nguyên Lâm Viên ở phía nam Tây Nguyên, có độ cao trung bình trên $1.500 \mathrm{~m}$, vì thế khí hậu mang đặc trưng là khí hậu Á nhiệt đới núi cao: Nhiệt độ trung bình hàng năm là $18.3^{\circ} \mathrm{C}$, lượng mưa trung bình là $1800 \mathrm{~mm}$ và chia làm hai mùa rõ rệt: Mùa mưa từ tháng 5 tới tháng 11; Mùa khô từ tháng 12 tới hết tháng 4 năm sau. Đất đai chủ yếu được phong hoá từ nhiều nguồn khác nhau như đá macma, đá trầm tích, đá biến chất... Địa hình bị cắt xẻ nhiều bởi những đồi núi cao, do đó đất đai có độ dốc lớn nên bị xói mòn nhiều. Với điều kiện tự nhiên như trên, thảm thực vật phát triển rất phong phú và đa dạng, bao gồm rừng lá kim, rừng hỗn giao lá kim lá rộng và rừng lá rộng, đó là điều kiện rất thuận lợi cho khu hệ nấm lớn nói chung và khu hệ nấm thuộc chi Coprinus Pers. et Gray nói riêng.

Chi nấm mực (Coprinus Pers. et Gray) là chi nấm rất đa dạng thuộc họ nấm phân (Coprinaceae) gồm khoảng 660 loài phân bố trên thế giới (Mycobank, 2016). Coprinus bắt nguồn từ tiếng Hy Lạp là “Kopros” nghĩa là phân (Redhead và ctg., 2001).

\footnotetext{
*Tác giả liên hệ: Email: dunglb@dlu.edu.vn
} 
Do đó, những loài thuộc chi này được tìm thấy phân bố chủ yếu trên phân. Tuy nhiên, những nấm này cũng được tìm thấy trên các cơ chất khác như đất, gỗ hoặc vụn hữu cơ vùi trong đất. Chính vì vậy, các loài nấm thuộc chi nấm mực có ý nghĩa quan trọng với vòng tuần hoàn vật chất trong tự nhiên, làm sạch môi trường, ngoài ra một số loài được sử dụng làm thực phẩm cho con người.

Năm 1797, chi nấm mực (Coprinus Pers. et Gray) chính thức được thành lập bởi Persoon và vị trí hệ thống học của chi nấm này được xác định như sau: chi nấm mực (Coprinus Pers. et Gray) thuộc họ nấm phân (Coprinaceae), bộ nấm tán (Agaricales)...

Từ khi được thành lập năm 1797 tới nay có rất nhiều tác giả nghiên cứu về vị trí hệ thống học và phân loại các loài trong chi Coprinus Pers. et Gray như Masse và Permington (1896); Bessey (1950); Lange (1953); Singer (1962, 1986); Gorlenko (1976); Alexopoulos (1996); Teng (1996); Hopple (1999); và Trịnh (1980, 1981, 2013), nhìn chung các tác giả trên đều thống nhất chi Coprinus Pers. et Gray là một chi lớn trong họ Coprinaceae của bộ Agaricales. Redhead và ctg. (2001), trong bài báo “Coprinus Persoon and the disposition of Coprinus species sensu lato", bằng Dẫn liệu về sinh học phân tử của các loài đã tách chi nấm mực [Coprinus Pers. et Gray, (1797)] thành 4 chi và xếp chúng vào 4 họ khác nhau trong bộ nấm tán (Agaricales): chi Coprinus sesu stricto thuộc họ nấm tán (Agaricaceae), Chi Coprinellus P. Karst. thuộc họ Psathyrellaceae, Chi Coprinopsis P. Karst. thuộc họ Psathyrellaceae và Chi Parasola thuộc họ là Psathyrellaceae. Năm 2001 cũng là một dấu mốc quan trọng giải đáp về nguồn gốc của các loài thuộc chi nấm mực [Coprinus Pers. et Gray, (1797)] và từ đây tạo điều kiện thuận lợi cho các nhà khoa học nghiên cứu chi nấm này. Tuy nhiên, quan điểm trên chưa được đông đảo các nhà khoa học trên thế giới thừa nhận. Do đó, trong nghiên cứu này chúng tôi theo quan điểm phân loại chi nấm mực (Coprinus Pers. et Gray) thuộc họ nấm phân (Coprinaceae), bộ nấm tán (Agaricaceae) của Trịnh (1980) và Singer (1986).

Ở Việt Nam đã có một số tác giả nghiên cứu về chi Coprinus sensu lato. Trịnh (1980, 1981, 2013) trong các công trình "Nấm lớn ở Việt Nam” đã công bố 32 loài. Phan (1996) trong luận văn tiến sĩ đã công bố 13 loài nấm chi Coprinus Pers. et Gray 
phân bố ở khu vực đồng bằng Bắc Bộ. Lê (2003) trong tác phẩm "Nấm lớn Tây Nguyên" đã công bố 2 loài.

\section{VẬT LIỆU VÀ PHƯƠNG PHÁP NGHIÊN CỨU}

\section{1. Đối tượng nghiên cứu}

Các loài thuộc chi Coprinus Pers. et Gray trên cao nguyên Lâm Viên.

\subsection{Phương pháp nghiên cứu}

\subsubsection{Thu thập, xủ lý và luu trũ tiêu bản nấm}

Thu thập tiêu bản nấm trên cao nguyên Lâm Viên và phân tích được thực hiện theo phương pháp của Trịnh (1980); Singer (1986); Teng (1996); và Lê (2003)... Tiêu bản được bảo quản trong dung dịch formalin 5\% và được lưu trữ trong phòng thí nghiệm Khoa Sinh học, Trường Đại học Đà lạt.

\subsubsection{Phân tích mẫu và định danh}

Phân tích đặc điểm hình thái ngoài sử dụng bảng so màu, kính lúp cầm tay... và phân tích đặc điểm hiển vi như bào tử, đảm, hệ sợi... sử dụng kính hiển vi soi nổi Olympus (Nhật Bản) tại Phòng thí nghiệm Khoa Sinh học, Trường Đại học Đà Lạt. Định danh theo phương pháp hình thái giải phẫu so sánh dựa trên tư liệu của các tác giả Trịnh (1980); Singer (1986); Teng (1996); và Lê (2003).

\section{KẾT QUẢ NGHIÊN CÚU}

Loài: Coprinus sterquilinus (Fr.) Fr., Epicrisis Systematis Mycologici: 242 (1838) Mycobank.

N. Y State Mus. Rep 24, p. 71 (1872); Kaufman (1918); Lê (2003); và Trịnh (2013).

Synonym: Agaricus sterquilinus Fr., Systema Mycologicum 1: 308 (1821).

Mũ nấm khi non dạng dù, khi già trải phẳng ra, có màu nâu tối, có vân thớ phóng xạ rõ rệt, trên mặt mũ có nhiều vảy lớn màu trắng, mép mũ rách không theo quy luật và cuối cùng cả mũ nấm tan ra thành nước đen như mực. Trên đỉnh mũ phủ dày đặc 
hạt màu nâu xen lẫn hạt màu trắng. Kích thước $5.0-5.5 \mathrm{~cm}$ đường kính. Hệ sợi mũ nấm có thành mỏng, màu tối, không có vách ngăn ngang, nội chất trong suốt, không hạt. Đường kính sợi $3.3-6.6 \mu \mathrm{m}$.

Cuống nấm dạng tròn trụ, gốc cuống phình dạng củ nhỏ, kích thước: dài 13.0 $14.5 \mathrm{~cm}$, đường kính $0.2-0.3 \mathrm{~cm}$, rỗng giữa. Bề mặt cuống nấm màu nâu tối và nhạt dần về gốc, không lông, không vảy. Trên cuống nấm có vòng nhỏ, màu nâu tối. Hệ sợi cuống nấm có thành tương đối dày, màu tối; nội chất có hạt nàu nâu sáng; có khóa; tần số bắt gặp sợi có vách ngăn ngang ít mà chủ yếu là sợi không có vách ngăn ngang.

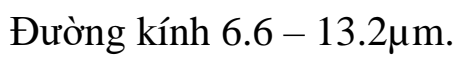

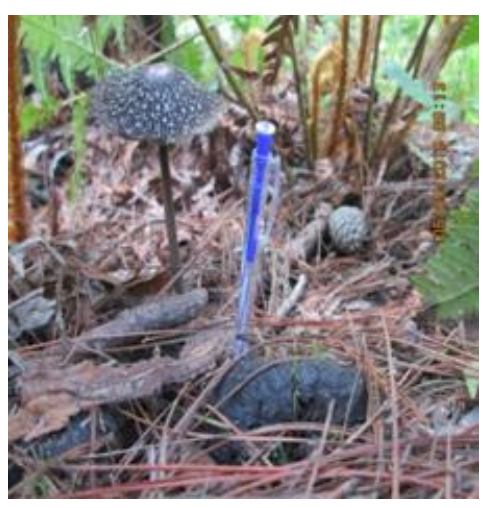

(a)

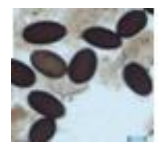

(b)

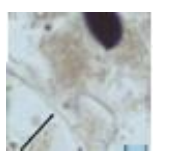

(c)

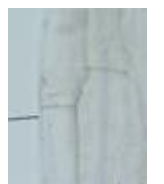

(d)

Hình 1. Loài Coprinus sterquilinus (Fr.)

Ghi chú: (a) Quả thể; (b) Bào tử; (c) Đảm và (d) Sợi nấm

Phiến tự do, khi già có màu đen và cùng với mũ nấm tan ra thành nước đen như mực. Hệ sợi phiến nấm có màng mỏng, trong suốt, màu tối; nội chất trong suốt không có hạt. Đường kính $3.3-3.5 \mu \mathrm{m}$.

Bào tử hình elip, màng dày, màu nâu tối tới màu đen sẫm, trong suốt; nội chất màu nâu tối, không có hạt; đỉnh có lỗ mầm lớn lệch đỉnh bào tử khoảng 5 độ. Kích thước $23.1-24.7 \times 13.2-14.8 \mu \mathrm{m}$.

Đảm hình chùy, nội chất trong suốt không có hạt. Kích thước 26.4 - 33.0 × 13.6 $-14.2 \mu \mathrm{m}$. 
Có nhiều liệt bào lớn, hình dùi trống với phần đế bè rộng, vách dày giống 2 lớp có màu vàng nhạt, nôi chất màu nâu nhạt. Kích thước $107.8-113.3 \times 3.3-4.9 \mu \mathrm{m}$.

Nấm thường mọc đơn độc trên phân ngựa dưới tán rừng thông vào mùa mưa. Nấm không có mùi.

Chưa rõ ý nghĩa.

Loài: Coprinus lagopus (Fr.) Fr., Epicrisis Systematis Mycologici: 250 (1838) Mycobank.

Trịnh (2003); và Amandeep và ctg. (2014).

Synonym: Agaricus lagopus Fr., Systema Mycologicum 1: 312 (1821) Mycobank, Coprinopsis lagopus (Fr.,) Redhead, Vilgalys \& Moncalvo, Taxon 50 (1): 229 (2001) Mycobank.

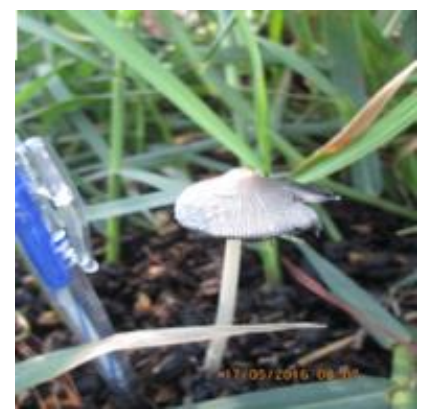

(a)

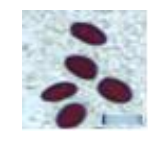

(b)

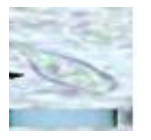

(c)

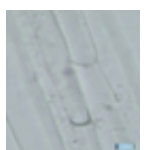

(d)

Hình 2. Loài Coprinus lagopus (Fr.)

Ghi chú: (a) Quả thể; (b) Bào tử; (c) Đảm và (d) Sợi nấm

Mũ nấm chất màng, khi non dạng chuông ngắn, già có hình ô dù, về sau trải phẳng, có vảy lớn màu trắng trên bề mặt, có vân thớ phóng xạ nông, mép mũ nấm rách không theo quy luật và quăn ngược lên phía đỉnh, kích thước mũ nấm $2.0-3.0 \mathrm{~cm}$ đường kính. Khi già mũ nấm tan ra thành nước đen như mực. Phía đỉnh mũ màu nâu nhạt, nhẵn. Mũ nấm màu xám da trâu đôi khi xám đậm. Hệ sơi mũ nấm có thành tương đối dày; nội chất trong suốt, không có hạt; không có vách ngăn ngang. Đường kính 3.3 $-6.6 \mu \mathrm{m}$. 
Cuống nấm dạng tròn, thót nhỏ dần về đỉnh cuống, có rễ nấm, dài $6-14 \mathrm{~cm}$, đường kính $3-5 \mathrm{~mm}$. Bề mặt cuống nấm màu trắng, mập, có nhiều lông mịn màu trắng, rỗng giữa. Trên cuống nấm không có vòng. Hệ sợi cuống nấm có thành mỏng, trong suốt; nội chất trong suốt, có nhiều hạt màu nâu nhạt; không có vách ngăn ngang và khóa. Đường kính $6.6-9.9 \mu \mathrm{m}$.

Phiến nấm tự do, khi non màu trắng, khi già có màu đen và cùng với mũ nấm tan ra thành nước đen như mực. Hệ sợi phiến nấm màng mỏng; nội chất trong suốt không

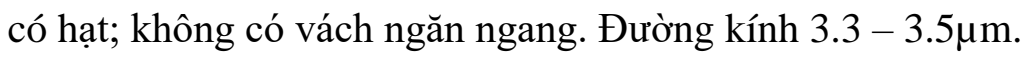

Bào tử hình elip, thành dày màu tối, trong suốt, nhẵn; nội chất màu nâu tối, không có hạt hay có từ 3 - 4 hạt màu tối; đỉnh có lỗ mầm nằm ở trung tâm đỉnh bào tử. Kích thước $12.2-13.2 \times 6.6-7.1 \mu \mathrm{m}$.

Đảm hình chùy, có màng dày màu tối; nội chất trong suốt, có hạt màu tối. Kích thước $12.5-13.0 \times 5.0-5.5 \mu \mathrm{m}$.

Trên phiến nấm có hai dạng liệt bào. Liệt bào loại Pleurocystidia có dạng elip thuôn dài hoặc gần trụ, màng mỏng, nội chất trong suốt không màu, kích thức 46.2 -

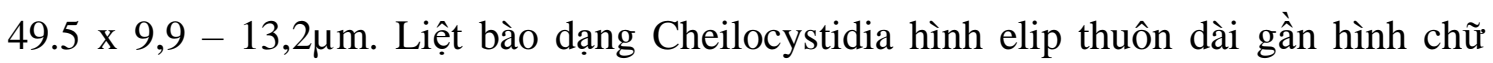
nhật, màng mỏng, nội chất trong suốt không màu, kích thước 26.4 - 33.0 x 13.2 $19.8 \mu \mathrm{m}$.

Nấm thường mọc đơn lẻ hay thành cụm liền chân hoặc rời chân trên vỏ cà phê, đất và xuất hiện vào mùa mưa với số lượng lớn. Nấm không có mùi.

Chưa rõ ý nghĩa.

Loài: Coprinus heterothrix Kuhner, Beulletin de la Société des Naturalistes d'Oyonnax 10 - 11: 3 (1957) Mycobank.

Abdullah và ctg. (2010) ; và Enderle và ctg. (1985).

Synonym: Coprinellus heterothrix (Kuhner) Redhead, Vigalys \& Moncalvo, Taxon 50 (1): 234 (2001). 
Mũ nấm 1/2 chất thịt, khi non hình trứng, trưởng thành hình nón, khi già trải phẳng ra, có vân thớ phóng xạ. Mũ nấm có màu xám, đỉnh mũ có màu nâu đỏ, mặt mũ có vân phóng xạ màu nâu từ đỉnh xuống mép mũ. Kích thước mũ nấm $1.8-2.0 \mathrm{~cm}$ đường kính. Hệ sợi mũ nấm có thành tương đối dày, màu tối; nội chất trong suốt có nhiều hạt màu vàng nhạt; không có vách ngăn ngang. Đường kính 3.3 - 6.6 $\mu \mathrm{m}$.

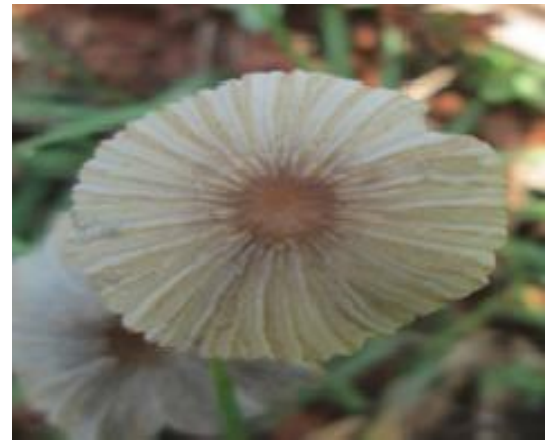

(a)

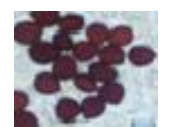

(b)

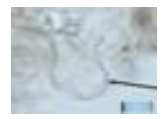

(c)

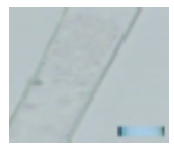

(d)

\section{Hình 3. Loài Coprinus heterothrix Kuhner}

Ghi chú: (a) Quả thể; (b) Bào tử; (c) Đảm và (d) Sợi nấm

Cuống nấm hình tròn hơi thót dần về phía đỉnh, giòn, dễ gãy, rỗng giữa. Bề mặt cuống nấm khi non màu trắng, có lông, khi già lông rụng hoàn toàn, cao $4.0-5.0 \mathrm{~cm}$. Không có vòng nấm và rễ nấm. Hệ sơi cuống nấm có màng mỏng, trong suốt; nội chất trong suốt không có hạt; tần suất bắt gặp sợi có vách ngăn ngang và khóa ít mà chủ yếu là sợi không có vách ngăn ngang. Đường kính 3.3 - 13.2 $\mu \mathrm{m}$.

Phiến nấm khi già có màu đen và cùng với mũ nấm héo lại chuyển toàn bộ sang đen. Phiến tự do. Hệ sợi phiến nấm có màng tương đối dày, màu tối; nội chất không có hạt; không có vách ngăn ngang. Đường kính 3.3 - 3.5 $\mu \mathrm{m}$.

Bào tử hình bầu dục hay hình trứng, màng dày màu tối, nhẵn, trong suốt; nội chất màu nâu tối, có nhiều hạt nhỏ màu tối; đỉnh có lỗ mầm nằm ở trung tâm đỉnh bào tử hay hơi lệch đỉnh bào tử 4 - 6 độ và làm cho đỉnh của bào tử nhọn hơn phía đối diện. Kích thước $12.8-13.2 \times 9.6-9.9 \mu \mathrm{m}$.

Đảm hình chùy, màng tương đối dày, màu tối, nội chất trong suốt có hạt. Kích thước $24.2-25.3 \times 13.0-13.2 \mu \mathrm{m}$. 
Có rất ít liệt bào, hình mũi mác, nội chất màu vàng, 2 lớp màng. Kích thước 52.0 $-52.8 \times 13.0-13.2 \mu \mathrm{m}$.

Nấm mọc thành cụm rời chân trên đất đồng cỏ, trên đất trồng trọt vào mùa mưa. Nấm không có mùi.

Chưa rõ ý nghĩa.

Loài: Coprinus disseminatus (Pers) Gray, A natural arrangement of British plants 1: 634 (1821) Mycobank.

Trịnh (2013); Phan (2012); và Lê (2012).

Synonym : Coprinellus disseminatus (Pers) J.E. Lange, Dansk bot. Ark. 9(no. 6): 93 (1938), Agaricus disseminatus Pers., Syn. Meth. Fung. (Gottingen) 2: 403 (1801) var disseminatus.

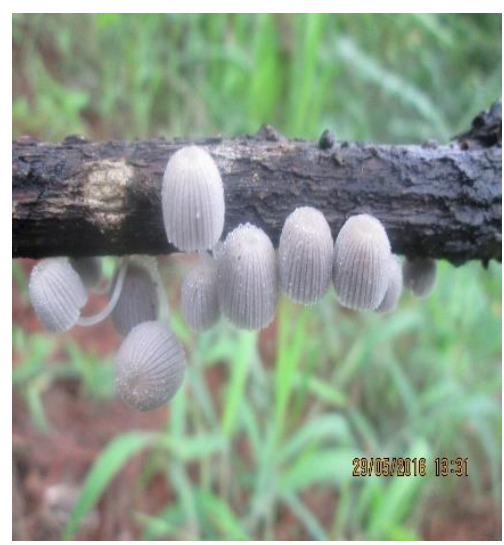

(a)

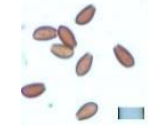

(b)

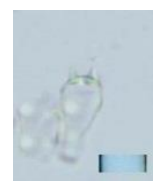

(c)

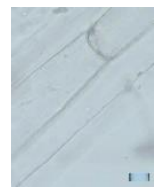

(d)

Hình 4. Loài Coprinus disseminatus (Pers) Gray

Ghi chú: (a) Quả thể; (b) Bào tử; (c) Đảm và (d) Sợi nấm

Mũ nấm khi non có hình chuông, trưởng thành dạng ô dù, khi già trải phẳng, có vân thớ phóng xạ. Mặt mũ nấm khi non có màu trắng, sau đó màu xám nhạt, cuối cùng là màu xám tro, bề mặt phủ dày đặc hạt và lông màu trắng. Đường kính mũ nấm $1.3-$ $1.5 \mathrm{~cm}$. Hệ sợi mũ nấm có thành tương đối dày, màu tối; nội chất trong suốt không có hạt; không có vách ngăn ngang. Đường kính $3.3-3.5 \mu \mathrm{m}$. 
Cuống nấm màu trắng, uốn cong không theo quy luật, rỗng giữa, cao 2.0 $2.5 \mathrm{~cm}$. Bề mặt cuống nấm có lông màu trắng, không có vòng nấm và rễ nấm. Hệ sợi cuống nấm từ thành mỏng đến thành dày, trong suốt, màu hơi tối; nội chất có hạt màu

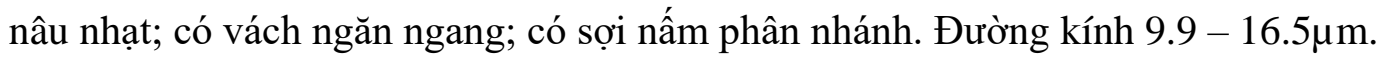

Phiến nấm đính, khi già có màu nâu cà phê. Hệ sợi phiến nấm có thành mỏng; nội chất trong suốt; không có vách ngăn ngang. Đường kính $3.3-3.5 \mu \mathrm{m}$.

Trên phiến nấm không tìm thấy liệt bào. Liệt bào trên mặt mũ (Dermatocistidia) hình chai hay hình trụ tròn ở đỉnh, màng mỏng, nội chất trong suốt không màu, kích thước $46.2-47.3$ x $9.9-11.0 \mu \mathrm{m}$.

Bào tử hình elip màng dày, màu tối, nhẵn, trong suốt; nội chất màu nâu nhạt (hay màu nâu cà phê), có nhiều hạt màu tối; đỉnh có lỗ mần lớn, sáng, nằm ở trung tâm đỉnh bào tử. Kích thước $9.7-9.9 \times 5.8-6.3 \mu \mathrm{m}$.

Đảm hình chùy màng dày màu tối; nội chất trong suốt, có nhiều hạt màu tối; đỉnh đảm có 4 cuống bào tử mang 4 bào tử đảm. Kích thước $19.5-20.9 \times 9.3-9.5 \mu \mathrm{m}$.

Nấm thường mọc thành cụm liền chân hoặc rời chân trên đất đồng cỏ, trên thân gỗ mục vào mùa mưa. Thường gặp với số lượng lớn. Nấm không có mùi.

Chưa rõ ý nghĩa.

Loài: Coprinus plicatilis (Curtis) Fr. Epicrisis Systematis Mycologici: 252 (1838).

Nagy (2010); Trịnh (2013); và Lê (2013).

Synonym: Agaricus plicatilis Curtis, Fl. Londin. (1787), Parasola plicatilis (Curtis) Redhead, Vilgalys \& Hopple Taxon 50 (1): 235 (2001).

Mũ nấm chất màng, trưởng thành dạng ô dù, khi già dạng nón dẹp, mép mũ nấm cuộn vào trong, kích thước mũ nấm $2.5-3.5 \mathrm{~cm}$ đường kính. Mặt mũ nấm có màu tro với vân thớ phóng xạ. Chóp mũ nấm phủ hạt màu nâu đậm đến nâu nhạt. Hệ sợi mũ 
nấm có thành tương đối dày, màu tối; không có vách ngăn ngang; nội chất trong suốt. Đường kính sợi $3.3-6.6 \mu \mathrm{m}$.

Cuống nấm hình trụ tròn hơi thót dần về phía đỉnh, cao $5.5-8.0 \mathrm{~cm}$, dường kính $2-3 \mathrm{~cm}$, khi già màu trắng ngà, bóng, đặc, chắc hay rỗng giữa, có lông màu trắng mịn ở gốc. Hệ sợi cuống nấm có thành mỏng, trong suốt, màu tối; nội chất có hạt màu hơi tím; có khóa; tần số bắt gặp sợi có vách ngăn ngang ít mà chủ yếu là sợi không có vách ngăn ngang. Đường kính sợi $6.6-13.2 \mu \mathrm{m}$.

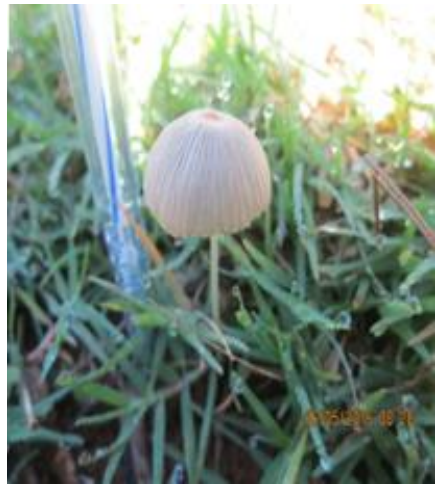

(a)

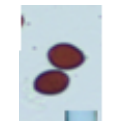

(b)

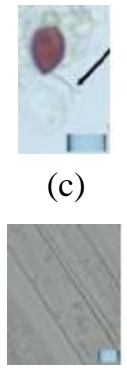

(d)

Hình 5. Loài Coprinus plicatilis

Ghi chú: (a) Quả thể; (b) Bào tử; (c) Đảm; (d) Sợi nấm

Phiến khi già có màu đen và cùng với phần thịt mỏng của mũ héo lại chuyển toàn bộ sang màu đen.

Hệ sợi phiến nấm có thành mỏng, màu tối; nội chất trong suốt chứa nhiều hạt nhỏ màu vàng nhạt; có vách ngăn ngang. Đường kính sợi $3.3-3.5 \mu \mathrm{m}$.

Bào tử hình elip hay dạng hạt đậu màng dày màu nâu, nhẵn, trong suốt; nội chất màu nâu tối, chứa nhiều hạt nhỏ; đỉnh có lỗ mầm lớn lệch đỉnh bào tử khoảng 20 độ. Kích thước $8.8-9.9$ x $6.6-7.7 \mu \mathrm{m}$.

Đảm hình chùy, nội chất trong suốt chứa các hạt nhỏ. Kích thước 29.7 - 30.6 x $17.5-17.6 \mu \mathrm{m}$.

Có nhiều liệt bào lớn, phần gần đỉnh hơi chẻ dạng răng và lớn hơn phần đế. Kích 
thước $170-200$ x $3.3-6.6 \mu \mathrm{m}$.

Nấm thường mọc đơn lẻ trên đất trồng trọt, ven đường, ngoài đồng cỏ, trong vườn vào mùa mưa. Thường gặp với số lượng nhiều. Nấm không có mùi.

Nấm được dùng làm thực phẩm khi non và không được uống rượu trong khi ăn.

Loài: Coprinus ephemeroides (Bull.) Fr., Epicrisis Systematis Mycologici: 250 (1838) Mycobank.

Enderle (1985); và Mykola (2011).

Synonym: Agaricus ephemeroidesBll., Flore francaise 2: 145 (1805) Mycobank, Coprinopsis ephemeroides (DC.) G. Moreno: 811 (2010) Mycobank.

Mũ nấm nhỏ, chất màng dễ nát, khi non hình gần cầu, sau đó trải phẳng và cuối cùng cuộn vào phía trong mũ nấm hay ngược lại, có vân thớ phóng xạ. Đỉnh mũ nấm màu nâu, xung quanh phủ dày đặc hạt màu trắng và các hạt này sẽ chuyển sang màu nâu nhạt khi nấm già. Giai đoạn đầu mũ nấm có màu trắng trong suốt, sau đó chuyển sang màu nâu nhạt và cuối cùng màu đen. Kích thước mũ nấm $0.4-0.6 \mathrm{~cm}$ đường kính. Hệ sợi phiến nấm có thành tương đối dày, trong suốt; nội chất trong suốt không có hạt; không có vách ngăn ngang. Đường kính 3.0 - 3.3 $\mu$ m.

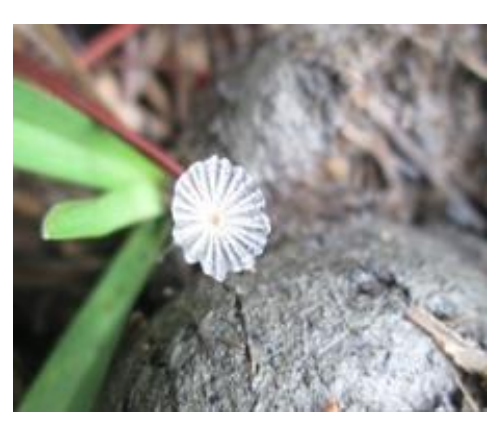

(a)

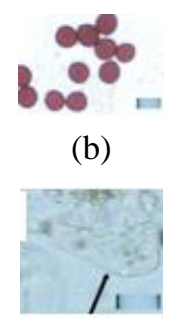

(c)

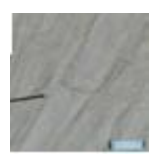

(d)

Hình 6. Loài Coprinus ephemeroides

(a) Quả thể; (b) Bào tử; (c) Đảm; (d) Sợi nấm

Cuống nấm màu trắng đục, dễ nát, rỗng giữa, có lông màu trắng rất mịn, cao 2.8 
- 3.0cm. Có vòng nấm tại vị trí 1⁄2 cuống nấm. Hệ sợi cuống nấm có thành mỏng; nội

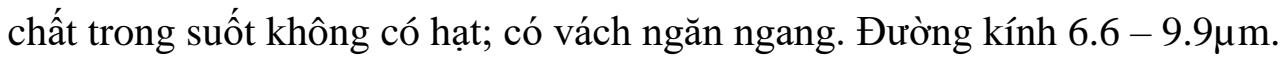

Phiến nấm tự do, khi non màu trắng, khi già héo lại có màu đen và tạo thành những đường dọc màu đen dưới mặt mũ nấm. Hệ sợi phiến nấm có thành tương đối dày; nội chất trong suốt không có hạt; không có vách ngăn ngang. Đường kính 3.0 - 3.3um.

Bào tử đa số hình cầu, ít khi dạng elip, màng dày, màu nâu tối; nội chất màu nâu tối, có nhiều hạt màu tối; đỉnh có lỗ nảy mầm nằm ở trung tâm đỉnh bào tử và làm cho 1 đỉnh bào tử nhọn hơn đỉnh đối diện. Kích thước $8.8-9.9 \times 7.9-8.2 \mu \mathrm{m}$.

Đảm hình chùy, có thành tương đối dày, có nhiều hạt màu tối. Kích thước 19.2 $19.8 \times 8.4-8.8 \mu \mathrm{m}$.

Có rất ít liệt bào, hình trụ dài, màng có 2 lớp vỏ, nội chất màu hơi tối. Kích thước 60 - $66 \times 6.3-6.6 \mu \mathrm{m}$.

Nấm hoại sinh trên phân dưới tán rừng thông vào mùa mưa, thường gặp với số lượng lớn. Nấm không có mùi.

Chưa rõ ý nghĩa.

\section{KẾT LUẬN}

Khu hệ nấm chi Coprinus Pers. et Gray trên cao nguyên Lâm viên có 6 loài: Coprinus sterquilinus (Fr.)Fr., Coprinus lagopus (Fr.)Fr., Coprinus heterothrix Kuhner., Coprinus disseminatus (Pers.) Gray, Coprinus plicatilis (Curtis)Fr. và Coprinus ephemeroides (Bull.) Fr. Chúng thường sống hoại sinh trên phân, trên đất hoặc trên gỗ mục nát. Mũ nấm chất màng đến chất thịt. Cuống nấm đính trung tâm, chất thịt hoặc chất xellulose, dễ tách khỏi mũ nấm, đôi khi dính liền mũ nấm. Phiến nấm tự do, hay phiến dính, rất mỏng, khi chín thì thối rữa thành nước màu đen, thường có liệt bào. Bào tử màu nâu tối đến màu đen.

\section{LỜI CẢM ƠN}

Chúng tôi xin chân thành cảm ơn Ban Giám hiệu Trường Đại học Đà Lạt; Cảm 
ơn tập thể cán bộ Khoa Sinh học, Trường Đại học Đà Lạt đã giúp đỡ chúng tôi trong việc thực hiện nghiên cứu và hoàn thành bài báo này.

\section{TÀI LIỆU THAM KHẢO}

Alexopoulos, C. J., Mims, C. W., \& Blackwell, M. (1996). Introductory Mycology (4th edition). New York, USA: Jon Wiley \& Sons Inc.

Bessey, E. A. (1950). Morphology and taxonomy of Gungy. New York, USA: Macmillan Publishing Co. Inc.

Nguyễn, V. C. (1985). Tây Nguyên - Các điều kiện tụ nhiên và tài nguyên thiên nhiên. Hà Nội, Việt Nam: NXB. Khoa học Kỹ thuật.

Phan, H. D. (1996). Nghiên cúu phân loại bộ Agaricales vùng đồng bằng Bắc Bộ Việt Nam. Luận án Tiến sỹ. Đại học Quốc gia Hà Nội.

Lê, B. D. (2003). Nấm lớn ở Tây Nguyên. Hà Nội, Việt Nam: NXB. Khoa học Kỹ thuật.

Gorlenko, M. V. (1976). Gribu (Myxomycota). Moskva.

Hopple, J. S., \& Vigalys, R. (1994). Phylogenetic relationships among coprinoid taxa and allies based on data from restriction site mapping of nuclear rDNA. Mycologia, 86, 96-107.

Hopple, J. S., \& Vigalys, R. (1999). Phylogenetic relationships the mushroom genus Coprinus and dark-spored allies based on sequence data from the nuclear gene coding for the large ribosomal subunit RNA: divergent domains, outgroups, and monophyly. Molec. Phylogenetic \& Evol, 13, 1-19.

Trịnh, T. K. (1980). Nấm lớn ở Việt Nam. Hà Nội, Việt Nam: NXB. Khoa học Kỹ thuật.

Trịnh, T. K. (1981). Nấm lớn ở Việt Nam (Tập I, tái bản lần thứ II). Hà Nội, Việt Nam: NXB. Khoa học Tự nhiên và Công nghệ.

Trịnh, T. K. (2013). Nấm lớn ở Việt Nam. Hà Nội, Việt Nam: NXB. Khoa học Tự nhiên và Công nghệ.

Redhead, S. A., R. Vilgalys, J. M., Moncalvo, Johnson, J., \& Hopple, J. S. (2000). Coprinus Persoon and the disposition of Coprinus species sensu lato. Taxon, 50, 203-241.

Singer, R. (1962). The Agaricales in modern taxonomy. New York, USA: Hafner Publishing Co.

Singer, R. (1986). The Agaricales in modern taxonomy (4th edition). Koenigste: Koeltz Scientific Books.

Lê, X. T., Phạm, N. D. (2013). Atlas nấm Cát Tiên (Tập 1). Đồng Nai, Việt Nam: Vườn Quốc gia Cát Tiên.

Teng, S. C. (1996). Fungy of China. New York, USA: Mycotaxon, LTD. Ithaca. 
PRELIMINARY STUDIES FUNGI GENUS COPRINUS PERS. ET GRAY FLORA ON THE LAMVIEN PLATEAU

\title{
Le Ba Dung ${ }^{\text {a* }}$, Le Khac Duan ${ }^{\text {a }}$
}

${ }^{a}$ The Faculty of Biology, Dalat University, Lamdong, Vietnam

Corresponding author: Email: dunglb@dlu.edu.vn

\section{Article history}

Received: July 01 ${ }^{\text {st }}, 2016 \mid$ Received in revised form: August $26^{\text {th }}, 2016$

Accepted: September $15^{\text {th }}, 2016$

\begin{abstract}
Coprinus Pers. et Gray flora on the Lamvien Plateau includes 6 following species: Coprinus sterquilinus (Fr.)Fr., Coprinus lagopus (Fr.)Fr., Coprinus heterothrix Kuhner., Coprinus disseminatus (Pers.)Gray Coprinus plicatilis (Curtis)Fr. and Coprinus ephemeroides (Bull.)Fr., in which Coprinus plicatilis (Curtis)Fr. is used as food. Coprinus fungi are saphrophytic fungi that usually grow on stool or on manure or soil during rainy seasons.
\end{abstract}

Keywords: Coprinus; Central Highlands; Lamvien; Vietnam. 